\title{
HUMAN-ORIENTED LEADERSHIP AND ORGANIZATIONAL COMMITMENT IN US SUBSIDIARY COMPANY BASED IN SARAWAK
}

\author{
Azman Ismail ${ }^{1}$; Yusniati Ishak ${ }^{2}$; Munirah Hanim Yusuf ${ }^{3}$ \\ ${ }^{1}$ Faculty of Economics \& Management, Universiti Kebangsaan Malaysia \\ Kampung Bangi, 43600 Bangi, Selangor, Malaysia \\ ${ }^{2}$ Graduate School of Business, Universiti Kebangsaan Malaysia \\ Kampung Bangi, 43600 Bangi, Selangor, Malaysia \\ ${ }^{3}$ Faculty of Science Cognitive \& Human Development, Universiti Malaysia Sarawak \\ Jalan Dato Mohd Musa, 94300 Kota Samarahan, Sarawak, Malaysia \\ 1azisma08@gmail.com; ²yuss294@gmail.com
}

Received: $2^{\text {th }}$ September 2016/ Revised: $3^{\text {th }}$ November 2016/ Accepted: $7^{\text {th }}$ November 2016

How to Cite: Ismail, A., Ishak, Y., \& Yusuf, M. H. (2016). Human-Oriented Leadership and Organizational Commitment in US Subsidiary Company Based in Sarawak. Binus Business Review, 7(3), 233-239. http://dx.doi.org/10.21512/bbr.v7i3.1752

\begin{abstract}
This article was conducted to examine the relationship between human-oriented leadership (HOL) and organizational commitment. A survey method was employed to obtain data from the employees of one US subsidiary company based in Sarawak. Results of the Partial Least Squares (SmartPLS) model analysis confirmed that participative leadership, supportive leadership, and empowerment act as important antecedents of organizational commitment. These findings reveal that the capability of managers practicing HOL styles (supportive, participative, and empowerment) has enhanced employees' commitment to the organization.
\end{abstract}

Keywords: participative leadership, supportive leadership, empowerment, organizational commitment

\section{INTRODUCTION}

Leadership is often viewed as a mechanism used by leaders to deal with followers towards achieving organizational goals and targets (Lussier \& Achua, 2016). Since employees come from different backgrounds with various job designations, leaders will practice different leadership styles towards their subordinates (Ismail et al., 2010). One of the salient leadership styles commonly practiced is HumanOriented Leadership (HOL) style which emphasizes on strong human relations with their employees such as giving special attention to their personal needs.

HOL behaviours are composed of two important elements namely supportive and participative (Tatlah, Ali, \& Saeed, 2011; Yiing \& Ahmad, 2009). Leaders with supportive behaviors demonstrate concern for employees' personal needs and welfare while participative leaders ask for their employees to be involved in the decision-making process, consult them for opinions and ideas, and integrate all suggestions for the survival of the organization as a whole (Northouse, 2007). Thus, as highlighted by House (1996), supportive leadership is viewed as the most effective leadership behaviors preferred by employees because it involves emotions and personal expectations to be taken into consideration by leaders and they will always prioritize their employees' satisfaction and happiness (Mahdi, Mohd, \& Almsafir, 2014). On the other hand, participative leadership will create a friendly and open work environment which indirectly motivates employees to work harder towards organization al goals accomplishment (Malik, 2013). Other than the study on the correlation between leadership style and organizational commitment, previous researchers also found significant relationship between empowerment and employee's commitment. Empowerment is a central topic which is very much 
crucial for management effectiveness for the survival of organization (Borghei et al., 2010). Empowerment is defined as increased intrinsic task motivation manifested in a set of four cognitions reflecting an individual's orientation to his or her work roles which are competence or self-efficacy (an individual's belief in his or her capability to perform activities with skills), impact (the degree to which an individual can influence strategic, administrative, or operate outcomes at work), meaning (the value of a work goal or purpose, judged in relation to an individual's own ideals or standards) and self-determination (an individual's sense of having choice in initiating and regulating action)' (Spreitzer, 1995).

Recent studies reveal that in an organization, the capability of managers to choose the most suitable leadership behaviours either supportive (i.e., appreciating and congratulating what has been done, helping their subordinates, explaining reasons for criticisms, and giving constructive criticisms) or participative (i.e., sharing ideas and opinions, integrating suggestion) in day-to-day operations while implementing the organisational policies objectives as well as gaining competitive advantage in the industry, may directly affect employees' commitment toward the organisation (Tatlah et al., 2011; Yiing \& Ahmad, 2009). Organizational commitment is defined as an employee's belief in the organization 's goals and values, preference of remaining in the organization and loyalty to the organization (Yiing \& Ahmad, 2009). Besides that, Allen \& Meyer (1990) classified organizational commitment into three components; affective, continuance, and normative commitment. Affective commitment refers to employees' emotional attachment to, identification with, and involvement in the organization (Allen \& Meyer, 1990; Meyer \& Allen, 1991). Secondly, continuance component refers to commitment based on the costs that employees associate with leaving the organization (Allen \& Meyer, 1990; Meyer \& Allen, 1991). Finally, normative component refers to employees' feelings of obligation to remain with the organization (Allen \& Meyer, 1990; Meyer \& Allen, 1991).

Although there have been studies examining the relationship between HOL, empowerment, and organizational commitment, there are very few published research works on HOL conducted in Malaysia with regards to its relationship with employees' commitment. Many studies are done that emphasized on the different approaches of leadership styles such as transformational leadership (idealized influence, inspirational motivation, intellectual stimulation, and individualized consideration), transactional leadership (contingent rewards and management-by-exception) and laissez-faire (Arshad et al., 2013; Bakar \& Mahmood, 2014; Ismail et al., 2011; Kuppusamy et al., 2010; Lian \& Tui, 2012; Lo et al., 2010; Nordin, 2011; Tajasom \& Ahmad, 2011). Thus, this factor caused this research to be conducted to explore the correlation between HOL, empowerment, and organizational commitment.
This research aims to examine the relationship between human-oriented leadership behaviors and employee's commitment. Specifically, the research objectives are to examine the relationship between: (1) supportive leadership and organizational commitment, (2) participative leadership and organizational commitment, and (3) empowerment and organizational commitment. This article discusses four important aspects; literature reviews, methodology, and results of data analysis, as well as discussion, implications, and conclusion.

The functions of HOL and empowerment as important antecedents to employee's behavioural outcomes for instance satisfaction and commitment are consistent with the thought of leadership theory namely Stodgill's (1963) leadership style theory, House and Mitchell's (1974) path-goal theory, Lawler's (1973) expectancy theory, Bandura's (1986) and Conger and Kanungo's (1988) self-efficacy theory. For example, Stodgill's (1963) leadership style theory clearly posits that when employees perceive that their needs, welfare, and relationship are well taken care of by their managers, they are highly motivated. In return, this will contribute to positive outcomes such as satisfaction and commitment.

Besides, House and Mitchell's (1974) path-goal theory asserts that leaders are responsible for creating an environment in which employees' behaviors are aligned together with organizational goals and ensuring that employees are well directed to goal's achievement (Wart \& Suino, 2007). The notion of these theories promotes that caring, clarity of goals and high-quality relationship are the cruxes of supportive and participative leadership styles.

Moreover, Lawler's (1973) expectancy theory explained that employees would be highly motivated in accomplishing tasks if they noticed that their contribution would result in an expected level of performance and thus would produce a favorable outcome. Furthermore, Bandura's (1986) self-efficacy theory posits, 'Individuals are empowered if their personal efficacy expectations are strengthened while their outcome expectations are not necessarily affected'. These theories reflected the element of empowerment as an important antecedent to organizational commitment.

These theories are supported by HOL research literature. For example, several studies on the relationship between leadership behaviour and organisational commitment are based on different samples such as a sample of 238 Malaysian UM MBA part-time students and researchers (Yiing \& Ahmad, 2009), 100 respondents of Qom companies (Borghei et al., 2010), 200 primary school teachers working in different districts in Ankara (Çokluk \& Yılmaz, 2010), 150 respondents among leaders and teachers in the Punjab public sector education department, Lahore, Pakistan (Tatlah et al., 2011), 52 employees of Khorasan Razavi Sport and Youth Administration (Aghaei et al., 2013) and 300 employees from various plantation companies in Malaysia (Mahdi et al., 2014). 
These studies displayed three important findings. First, the capability of leaders practicing supportive leadership style (i.e., displaying concern for their needs and creating friendly work environment) contributed to employees' commitment to an organization. Second, the leaders who displayed participative leadership behaviors (i.e., consulting subordinate for opinions, provide suggestion and give advice) while exercising management functions affected the level of individual's commitment to an organization. Lastly, the evidence revealed that the willingness of leaders in considering employees' participation and involvement might generate significant impact to the organization and thus increasing employees' commitment towards the organization. Therefore, based on the literature, three hypotheses can be derived:

H1: There is a positive relationship between supportive leadership and organizational commitment.

$\mathrm{H} 2$ : There is a positive relationship between participative leadership and organizational commitment.

H3: There is a positive relationship between empowerment and organizational commitment.

\section{METHODS}

This research used a cross-sectional research design which enables the researchers to integrate leadership literature and the actual survey as the main procedure for data collection. Those methods may gather accurate and less biased data (Creswell, 2014; Sekaran \& Bougie, 2015). This approach is appropriate for researchers to gather accurate data, reduce bias and increase the quality of data collected (Sekaran \& Bougie, 2015). This research was conducted on employees at a US subsidiary company in Sarawak which is well-known as the largest airfreight exporter in Malaysia. This research aimed to provide empirical evidence of HOL practice by measuring the predicting variables of HOL in airfreight service providers.

Initially, the researchers prepared the questionnaires based on the HOL literature. Then, the contents of the questionnaire were discussed to be given second opinions by three experienced employees to understand the adaptation of HOL styles in achieving the organization's strategies and goals. Based on the discussion or interview session, the researchers were briefed on the categories of the staff in the organization. They were grouped into two major categories: management employees and supporting employees. Management employees are considered as the leaders (i.e., department heads, assistant department heads and supervisors) which are responsible for the management functions such as planning, organizing, leading and monitoring the supporting employees who are hired for assisting their managers to achieve the organizational goals and objectives. A back-translation technique was employed to translate the survey questionnaires into English and Malay languages to increase the validity and ensure the reliability of research findings (Creswell, 2014; Sekaran \& Bougie, 2015).

The survey questionnaire designed consisted of three sections meant for four constructs included in this study. The first section intended to measure supportive leadership (SLP) and participative leadership (PLP). It consisted of three items for supportive leadership and five items for participative leadership adapted from the multifactor leadership questionnaires (Bass, 1994, 1999; Bycio et al., 1995; Hartog et al., 1997; Dionne et al., 2004).

Then, the psychological empowerment (PEP) is measured using three items that are modified from empowerment literature which is Ashforth's (1989) helplessness scale, Hackman \& Oldham's (1980) autonomy scale and Jones's (1986) self-efficacy scale. Finally, the organizational commitment (OCT) is measured by six items that are developed by Mowday et al., (1979) called Organisational Commitment Questionnaire. All items are rated using 7 points Likert scale ranging from (1) "strongly disagree" to (7) "strongly agree." Demographic variables are used as controlling variables because this study also focused on employees' attitudes.

The researchers managed to collect $100(40 \%)$ eligible questionnaires out of 250 distributed to the employees of one US subsidiary company in Sarawak based on a purposive sampling technique. This sampling technique was chosen because it the best way of getting some basic information quickly and efficiently (Sekaran \& Bougie, 2015). The number of samples exceeded the minimum standard of $30 \%$ for inferential statistics. The survey questionnaires were answered by participants based on their consents and a voluntary basis.

For data analysis purpose, this study used the SmartPLS3.0 to assess the psychometric of survey questionnaire data and to test the research hypotheses. The main advantage of applying this analysis technique is, it may deliver latent variable scores, avoid small sample size problems, estimate every complex model with many latent and manifest variables, hassle stringent assumptions about the distribution of variables and error terms, and handle both reflective and formative measurement models (Henseler et al., 2009). The SmartPLS path model was employed to assess the magnitude and nature of the relationship between several independent variables and one or more dependent variables in the structural model using the standardized beta $(\beta)$ and $t$ statistics. The value of $\mathrm{R}^{2}$ is used as an indicator of the overall predictive strength of the model. The values of $\mathrm{R}^{2}$ are considered as the following; 0,19 (weak), 0,33 (moderate) and 0,67 (substantial) as suggested by Chin (1998) and (Henseler et al. 2009). Then, the value of $\mathrm{q}^{2}$ is used as a criterion to assess the model's predictive relevance (i.e., 0.02 (weak), 0,15 (medium) and 0,35 (large) (Hair et al., 2014). Lastly, the value 
of $\mathrm{f}^{2}$ is used as a measure to determine the effect size of the variable in the model (i.e., 0,02 (weak), 0,15 (medium) and 0,35 (large) (Hair et al., 2014).

\section{RESULTS AND DISCUSSIONS}

The majority of respondents are male (64\%), $33 \%$ within the range of $26-30$ years old and $44 \%$ of the respondents are Malay. Regarding respondents' education level, $33 \%$ of the respondents are diploma holders and $27 \%$ of them have worked more than 10 years.

Table 1 shows the average variance extracted (AVE) for each construct exceeded 0,50 and this is consistent with (Fornell \& Larcker, 1981) guidelines. This result indicates that all constructs met the acceptable standard of convergent validity (Barclay, Higgins, \& Thompson, 1995; Fornell \& Larcker, 1981; Henseler et al., 2009). This reports on the results of testing discriminant validity of the measured scales. The elements in the matrix diagonals, representing the square roots of the AVEs, are greater in all cases than off-diagonal elements in their corresponding row and column, supporting the discriminant validity of our scales.

Table 1 The Results of Discriminant and Convergent Validity Analysis

\begin{tabular}{llllll}
\hline Constructs & AVE & SLP & PLP & PEP & OCT \\
\hline SLP & 0,785 & $\mathbf{0 , 8 8 6}$ & & & \\
PLP & 0,743 & 0,890 & $\mathbf{0 , 8 6 2}$ & & \\
PEP & 0,614 & 0,364 & 0,389 & $\mathbf{0 , 7 8 4}$ & \\
OCT & 0,689 & 0,511 & 0,509 & 0,365 & $\mathbf{0 , 8 3 0}$ \\
\hline
\end{tabular}

Table 2 shows the factor loadings and crossloadings for different constructs. The correlation between items and factors had higher loadings than other items in the different concepts, as well as the loadings of variables were greater than 0,70 in their constructs in the model which are considered adequate (Henseler et al. 2009). Overall, this result indicates that all items meet acceptable standard of discriminant validity (Fornell \& Larcker, 1981). Meanwhile, the values of composite reliability for all constructs were greater than 0,80 , indicating that instrument used in this study had high internal consistency (Hair et al., 2014).

Table 2 The Results of Constructs' Factor and Cross Loadings

\begin{tabular}{|c|c|c|c|c|c|}
\hline \multirow{2}{*}{ Constructs } & \multicolumn{4}{|c|}{ Cross Factor Loadings } & \multirow{2}{*}{$\begin{array}{l}\text { Composite } \\
\text { Reliability }\end{array}$} \\
\hline & SLP & PLP & РEP & & \\
\hline SLP & $\begin{array}{l}0,880- \\
0,892\end{array}$ & & OCT & & 0,916 \\
\hline PLP & & $\begin{array}{l}0,825- \\
0,896\end{array}$ & & & 0,935 \\
\hline PEP & & & $\begin{array}{l}0,775- \\
0,792\end{array}$ & & 0,827 \\
\hline OCT & & & & $\begin{array}{l}0,785- \\
0.879\end{array}$ & 0,930 \\
\hline
\end{tabular}

Table 3 shows that means for all constructs ranged from 4,44 to 4,99 , signifying that majority respondents perceived that the levels of SLP, PLP, PEP and OCT ranged from high (4) to highest level (7) in the organization. Furthermore, values of variance inflation factor for the relationship between the independent variables (i.e., SLP, PLP \& PEP) and OCT were less than 5,0, signifying that data were not affected by serious collinearity problem (Hair et al., 2014). These results further confirmed that the instruments used have met the acceptable standards of validity and reliability analyses.

Table 3 The Results of Variance Inflation Factor \& Descriptive Statistics

\begin{tabular}{cccc}
\hline Constructs & Mean & $\begin{array}{c}\text { Standard } \\
\text { Deviation }\end{array}$ & $\begin{array}{c}\text { Variance } \\
\text { Inflation Factor }\end{array}$ \\
\hline SLP & 4,97 & 1,41 & 4,805 \\
PLP & 4,99 & 1,43 & 4,915 \\
PEP & 4,86 & 1,22 & 1,181 \\
OCT & 4,44 & 1,30 & \\
\hline
\end{tabular}

Figure 1 presents outcomes of testing a direct effects model using SmartPLS. The inclusion of SLP in the analysis explained $26 \%$ of the variance in the dependent variable. Specifically, the result of SmartPLS path analysis revealed that SLP was positively and significantly correlated with OCT ( $\beta$ $=0,513, \mathrm{t}=6,612)$. Therefore H1 is supported. This result demonstrates that SLP is an important antecedent of OCT in the studied organization.

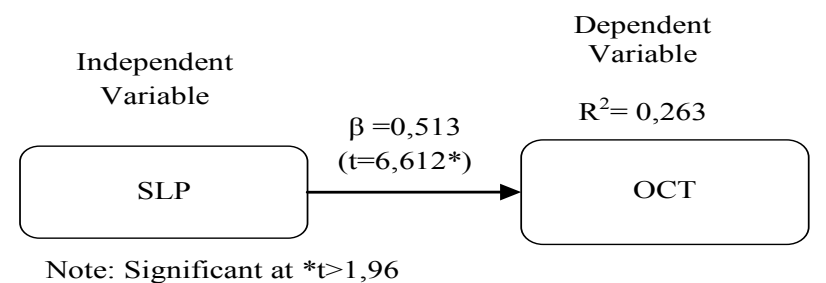

Figure 1 The Outcomes of Testing H1

As an extension of hypotheses testing, other tests were further conducted to determine the effect sizes for all construct, overall predictive strength of the model and predictive relevance for the reflective endogenous latent variable in the hypothesized model. The result of testing effect size $\left(\mathrm{f}^{2}\right)$ showed that SLP had bigger $\mathrm{f}^{2}$ value of 0,357 which was more than 0,35 (Hair et al., 2014), indicating that it had medium effect. Besides that, the value of $\mathrm{R}^{2}$ for OCT was less than 0,33 (Henseler et al., 2009), signifying that overall predictive strength of the model was weak. Regarding the explanatory power, a test of predictive relevance for the reflective endogenous latent variable was further conducted based on Stone-Geisser's formulae: $\mathrm{q}^{2}=\mathrm{Q} 2$ included - Q2 excluded/1-Q2 (Hair et al., 2014). The $\mathrm{q}^{2}$ value for OCT was less than 0,35 , 
showing that it had medium predictive relevance (Hair et al., 2014).

Figure 2 presents outcomes of testing a direct effect using SmartPLS. The inclusion of PLP in the analysis explained $26 \%$ of the variance in the dependent variable. Specifically, the result of SmartPLS path analysis displayed that PLP was positively and significantly correlated with OCT $(B=$ $0.509, \mathrm{t}=6.164$ ), therefore $\mathrm{H} 2$ is supported. This result demonstrates that PLP is an important determinant of OCT in the studied organization.

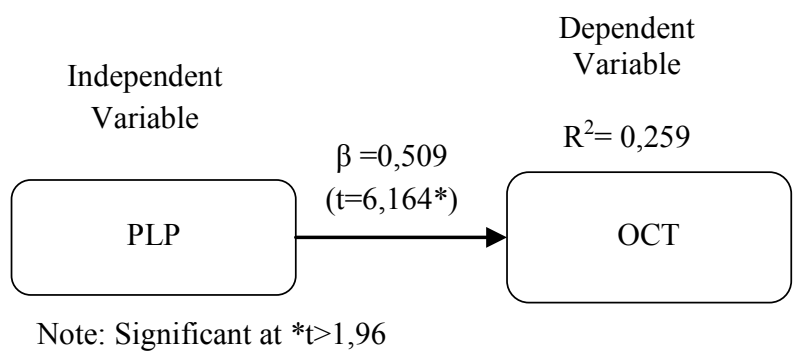

Figure 2 The Outcomes of Testing H2

Other tests were further conducted to determine the effect sizes for all construct, overall predictive strength of the model and predictive relevance for the reflective endogenous latent variable in the hypothesized model. The result of testing effect size $\left(\mathrm{f}^{2}\right)$ showed that PLP had bigger $\mathrm{f}^{2}$ value of 0,35 , indicating that it had medium effect (Hair et al., 2014). Besides that, the value of $\mathrm{R}^{2}$ for OCT was 0,259 which less than 0,33 (Henseler et al., 2009), signifying that the overall predictive strength of the model was weak. In terms of explanatory power, the $\mathrm{q}^{2}$ value for OCT was less than 0,35 , showing that it had medium predictive relevance (Hair et al., 2014).

Figure 3 presents outcomes of testing a direct effect using SmartPLS. The inclusion of PEP in the analysis explained $15 \%$ of the variance in the dependent variable. Specifically, the result of SmartPLS path analysis highlighted that PEP was positively and significantly correlated with OCT $(B=0,381 ; t=4,216)$. Therefore, H3 is supported. This result demonstrates that PEP is an important determinant of OCT in the organization.

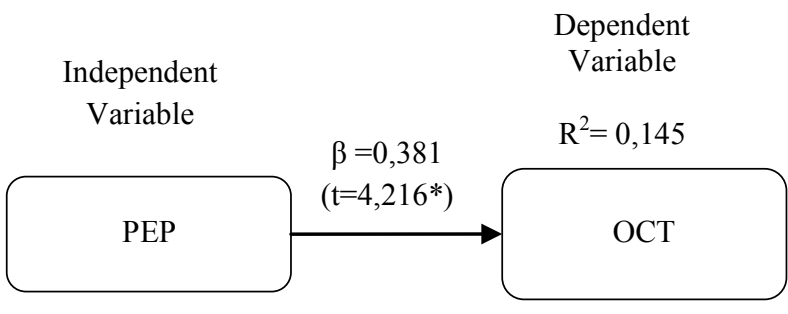

Note: Significant at $*_{\mathrm{t}}>1,96$

Figure 3 The Outcomes of Testing H3
Besides that, other tests were further conducted to determine the effect sizes for all construct, overall predictive strength of the model and predictive relevance for the reflective endogenous latent variable in the hypothesized model. The result of testing effect size $\left(\mathrm{f}^{2}\right)$ showed that PEP had $\mathrm{f}^{2}$ value of 0,170 which was less than 0,35 (Hair et al., 2014), indicating that it had a medium effect. Besides that, the value of $\mathrm{R}^{2}$ for OCT was less than 0,19 (Henseler et al., 2009), signifying that overall predictive strength of the model was weak. In terms of explanatory power, the $\mathrm{q}^{2}$ value for OCT was 0,081 which was less than 0,35 , showing that it had medium predictive relevance (Hair et al., 2014).

This research has examined the correlation between SLP, PLP, and PEP with OCT. The test carried out during the research confirmed the hypotheses. As a conclusion, the three constructs are among the antecedents of employees' commitment to an organization. As leaders are responsible for ensuring all organizational targets are achieved, practicing SLP and PLP during day-to-day operation and in the decision-making process and promoting positive feelings of PEP among organization's members may lead to greater OCT and eventually contribute to the organization success.

This research provides three major implications: theoretical, robustness of research methodology, and practical contributions. In term of theoretical contribution, the research reveals that management practices such as SLP, PLP and PEP are important antecedents of OCT. The findings of this study also have supported and broadened studies by (Çokluk \& Y1lmaz, 2010; Yiing \& Ahmad, 2009; Mahdi et al., 2014; Tatlah et al., 2011).

On the robustness of research methodology, the survey questionnaire used in this study has exceeded the acceptable standards of validity and reliability analysis. Thus it will be accurate, and the findings are reliable. This research addresses issues of SPP, PLP, and PEP. The findings of this study provided empirical support on SLP and employees outcomes in organizations where such knowledge can benefit the practitioners in the industry for the purpose of selecting and developing effective leaders as well as managing employee attitudes and behaviors towards achieving the organizational targets (Kim et al., 2013). It also provides the empirical evidence to support the view that direct PLP practiced by leaders towards the followers will give a positive impact on the OCT. In addition to that, managers also should emphasize on manipulating the elements of meaningful, competence, self-determined and impact.

\section{CONCLUSIONS}

This research tested a conceptual framework based on HOL literature and the statistical results have proven that there is significant relationship between HOL and OCT. It can be concluded that improvement 
in the HOL behaviour may lead to better employees' commitment. Eventhough SLP and PLP behaviours are not the only antecedents of OCT, they give positive effects. Therefore, these positive outcomes may contribute to gain employees' support for the survival of organisational competitiveness in the challenging global economy.

This research has several limitations: first, a cross-sectional research design used in this study may not capture causal connections between the variables of interest. Second, the outcomes of SmartPLS path model analysis have not measured the relationship between specific indicators for the independent variable, moderating variable and dependent variable. Third, although the results of survey questionnaire are useful to understand the intensity of respondents' emotions about the topic of this study, it is difficult to control respondent biases in answering the questionnaires. Finally, the sample for this study was only taken from respondents through non-probability sampling techniques at one organisational sector. Thus, these limitations may cause the results unsuitable to be generalised to other organisational settings.

This research provides some important suggestion to improve future research: first, several respondent characteristics should be further explored to show meaningful perspectives in understanding how individual similarities and differences influence the practice of HOL in organisations. Second, other research designs (e.g., longitudinal studies) should be utilized to collect data and describe the patterns of change and the direction and magnitude of causal relationships amongst variables of interest. Finally, response bias and common-method variance is a known issue in survey method. To reduce the effects ofthis weakness, the use of a larger sample size should be taken into consideration. The significance of these issues needs to be further explored in future study to provide a wider perspective.

\section{REFERENCES}

Aghaei, M., Talebpour, M., Taheri, H., Mirzazadeh, Z. S., \& Rezaeian, M. (2013). Relationship between employees empowerment with organizational commitment in employess of Khorasan Razavi sport and youth administration. Research in Sport Management, 1(6), 217-220.

Allen, N. J., \& Meyer, J. P. (1990). The measurement and antecedents of affective, continuance and normative commitment to the organization. Journal of Occupational Psychology, 63, 1-18.

Arshad,A. S., Rasli, A., Mustafar, M., \& Norhalim, N. (2013). An exploratory study of Malaysian Technologybased firms leadership. Jurnal Teknologi, 3, 93-97.

Ashforth, B. E. (1989). The experience of powerlessness in organizations. Organizational behavior and human decision processes, 43(2), 207-242

Bakar, M. S., \& Mahmood, R. (2014). Linking transformational leadership and corporate entrepreneurship to performance in the public higher education institutions in Malaysia. Advances in Management \& Applied Economics, 4(3), 109-122.

Barclay, D., Higgins, C., \& Thompson, R. (1995). The Partial Least Squares (PLS) approach to causal modeling: Personal computer adoption and use as an illustration. Technology Studies, 2(2), 285-309.

Bass, B. M. (1994). Transformational leadership and team and organizational decision making. Sage: Thousand Oaks.

Bass, B. M. (1999). Two decades of research and development in transformational leadership. European Journal of Work and Organizational Psychology, 8(1), 9-32.

Borghei, R., Jandaghi, G., Matin, H., \& Dastani, N. (2010). An examination of the relationship between empowerment and organizational commitment. International Journal of Human Sciences, 7(2), 1156-1170.

Bycio, P., Hackett, R. D., \& Allen, J. S. (1995). Further assessments of Bass's (1985) conceptualization of transactional and transformational leadership. Journal of Applied Psychology, 80(4), 468-478. http://doi.org/10.1037/0021-9010.80.4.468

Chin, W. W. (1998). The Partial Least Squares approach to Structural Equation Modeling. Modern methods for business research, 295(2), 295-336.

Çokluk, Ö., \& Yılmaz, K. (2010). The Relationship between leadership behavior and organizational commitment in Turkish primary schools. Bilig, 54, 75-92.

Creswell, J. W. (2014). Research design: Qualitative, quantitative and mixed methods approaches (Fourth edi). Carlifornia: SAGE Publication.

Den Hartog, D. N., Van Muijen, J. J., \& Koopman, P. L. (1997). Transactional versus transformational leadership: An analysis of the MLQ. Journal of Occupational and Organizational Psychology, 70(1997), 19-34. http://doi.org/10.1111/j.2044-8325.1997.tb00628.x

Dionne, S. D., Yammarino, F. J., \& Spangler, W. D. (2004). Transformational leadership and team performance. Journal of Organizational Change, 17(2), 177-193. http://doi.org/10.1108/09534810410530601

Fornell, C., \& Larcker, D. F. (1981). Evaluating structural equation models with unobservable variables and measurement error. Journal of Marketing Research, XVIII, 39-50.

Hackman, J. R., \& Oldham, G. R. (1980). Work redesign. MA: Addison-Wesley.

Henseler, J., Ringle, C. M., \& Sinkovics, R. R. (2009). The use of partial least squares path modeling in international marketing. Advances in International Marketing, 20, 277-319. http://doi. org/10.1016/0167-8116(92)90003-4

House, R. J. (1996). Path-goal theory of leadership: Lessons, legacy, and a reformulated theory. Leadership Quarterly, 7(3), 323-352. http://doi.org/10.1016/ S1048-9843(96)90024-7

Ismail, A., Mohamed, H. A.-B., Sulaiman, A. Z., Mohamad, M. H., \& Yusuf, M. H. (2011). An empirical study of the relationship between transformational leadership, empowerment and organizational commitment. Business and Economics Reserach Journal, 2(1), 
89-107.

Ismail, A., Zainuddin, N., \& Ibrahim, Z. (2010). Linking participative and consultative leadership styles to organizational commitment as an antecedent of job satisfaction. UNITAR E-Journal, 6(1), 11-26. Retrieved from https://lopes.idm.oclc.org/ login?url=http://search.ebscohost.com/login.aspx ?direct $=$ true $\& \mathrm{db}=\mathrm{a} 9 \mathrm{~h} \& \mathrm{AN}=51444631 \&$ site $=$ edslive \&scope $=$ site

Jones, G. R. (1986). Socialization tactics, self-efficacy, and newcomers' adjustments to organizations. Academy of Management Journal, 29(2), 262-279. http://doi. org/10.2307/256188

Joseph F. Hair, J., Hult, G. T. M., Ringle, C., \& Sarstedt, M. (2014). A primer on Partial Least Squares Structural Equation Modeling (PLS-SEM). Sage: Thousand Oaks.

Jr., J. F. H., Black, W. C., Babin, B. J., \& Anderson, R. E. (2014). Multivariate data analysis ( $7^{\text {th }}$ ed.). Pearson.

Jr, J. F. H., Sarstedt, M., Hopkins, L., \& Kuppelwieser, V. G. (2014). Partial Least Squares Structural Equation Modeling (PLS-SEM). European Business Review, 26(2), 106-121. http://doi.org/10.1108/EBR-102013-0128

Kim, S., Egan, T. M., Kim, W., \& Kim, J. (2013). The impact of managerial coaching behavior on employee work-related reactions. Journal of Business and Psychology, 28(3), 315-330. http://doi.org/10.1007/ s10869-013-9286-9

Kuppusamy, J., Ganesan, J., \& Rosada, S. (2010). Leadership styles and management techniques: an analysis of Malaysian women entrepreneurs. Communications of the IBIMA, 2010, 1-10. http:// doi.org/10.5171/2010.817881

Lian, L. K., \& Tui, L. G. (2012). Leadership styles and organizational citizenship behavior: the mediating effect of subordinates' competence and downward influence tactics. Journal of Applied Business and Economics, 13(2), 59-96. Retrieved from http:// www.na-businesspress.com/JABE/LianLK Web13_2_.pdf

Lo, M.-C., Ramayah, T., Min, H. W., \& Songan, P. (2010). The relationship between leadership styles and organizational commitment in Malaysia: role of leader-member exchange. Asia Pacific Business Review, 16(1-2), 79-103. http://doi. org/10.1080/13602380903355676

Lussier, R. N., \& Achua, C. F. (2016). Leadership: Theory, application \& skill development (Sixth Edit). United States: Cengage Learning.

Mahdi, O. R., Mohd, E. S. B. G., \& Almsafir, M. K. (2014). Empirical study on the impact of leadership behavior on organizational commitment in plantation companies in Malaysia. Procedia - Social and Behavioral Sciences, 109, 1076-1087. http://doi. org/10.1016/j.sbspro.2013.12.591

Malik, S. H. (2013). Relationship between leader behaviors and employees' job satisfaction: A path-goal approach. Pakistan Journal of Commerce and Social Sciences, 7(1), 209-222.

Meyer, J. P., \& Allen, N. J. (1991). A three-component conceptualization of organizational commitment. Human Resource Management Review, 1(1), 61-89.

Mowday, R. T., Steers, R. M., \& Porter, L. W. (1979). The measurement of organizational commitment. Journal of Vocational Behavior, 14, 224-247.

Nordin, N. (2011). The influence of emotional intelligence, leadership behaviour and organizational commitment on organizational readiness for change in higher learning institution. Procedia - Social and Behavioral Sciences, 29, 129-138. http://doi. org/10.1016/j.sbspro.2011.11.217

Northouse, P. G. (2007). Leadership: Theory and practice (4th Edition). Thousand Oak: SAGE Publication.

Sekaran, U., \& Bougie, R. (2015). Research methods for business: A skill-building approach (Sixth Edit). New Delhi.

Spreitzer, G. M. (1995). Psychological empowerment in the workplace: Dimensions, measurement, and validation. Academy of Management Journal, 38(5), 1442-1465.

Tajasom, A., \& Ahmad, Z. A. (2011). Principals' leadership style and school climate: Teachers' perspectives from Malaysia. The International Journal of Leadership in Public Services, 7(4), 314-333. http:// doi.org/10.1108/17479881111194198

Tatlah, I.A.,Ali, Z., \& Saeed, M. (2011). Leadership behavior and organizational commitment: An empirical study of educational professionals. International Journal of Academic Research, 3(2), 1293-1299.

Wart, M. Van, \& Suino, P. (2007). Leadership in public organizations: An introduction. New York: M. E. Sharpe.

Yiing, L. H., \& Ahmad, K. Z. (2009). The moderating effects of organizational culture on the relationships between leadership behaviour and organizational commitment and between organizational commitment and job satisfaction and performance. Leadership \& Organization Development Journal, 30(1), 53-86. http://doi.org/10.1108/01437730910927106 